\title{
High doses of phytase on growth performance and apparent ileal amino acid digest- ibility of broilers fed diets with graded concentrations of digestible lysine
}

\author{
Carrie L. Walk, ${ }^{* 1}$ and Savaram Venkata Rama $\operatorname{Rao}^{\dagger}$ \\ *AB Vista, Marlborough, Wiltshire SN8 4AN, UK; and `Sri Ramadhootha Poultry Research Farm Pvt Ltd, \\ Hyderabad, India
}

\begin{abstract}
Two experiments of the same design were conducted to determine the influence of phytase on performance and apparent ileal digestibility (AID) of amino acids in broilers fed graded concentrations of digestible lysine (dgLys). Cobb 400, male broilers were allocated to 1 of 16 diets consisting of 4 basal diets formulated at $80,88,96$, or $104 \%$ of the Cobb 400 dgLys requirements for each feeding phase. Phytase was included in each basal diet at 0 , $750,1,500$, or 3,000 phytase units (FTU)/kg. In Exp. 1, 33 birds/pen from hatch to day 42 were fed a 2-phase feeding program with 12 replicate pens/diet. In Exp. 2, there were 25 birds/pen from hatch to day 21 and 8 replicate pens/diet. Data were analyzed as a $4 \times 4$ factorial and means separated using orthogonal contrasts. In Exp. 1, feed intake $(\mathbf{F I})$ increased (quadratic, $P<0.05$ ) as dgLys increased in the diet. Body weight gain (BWG) increased (quadratic, $P<0.05$ ) as dgLys concentration or phytase dose increased in the diet. As phytase dose increased in the diet, feed conversion ratio (FCR) was improved in a linear or quadratic $(P<0.05)$ manner depending on the dgLys concentration of the diet (dgLys $\times$
\end{abstract}

phytase, $\mathrm{P}<0.05)$. In Exp. 2, FI linearly $(P<0.05)$ increased as dgLys increased in the diet. Increasing the concentration of dgLys or phytase in the diet increased (quadratic, $P<0.05$ ) BWG and improved (quadratic, $P<0.05$ ) FCR. The AID of most amino acids was influenced by a dgLys $\times$ phytase interaction $(P<0.05)$, except threonine, valine, tryptophan, serine, cysteine, or leucine (linear or quadratic effect of phytase, $P<0.05$ ), where phytase improved the AID in birds fed diets containing 80,88 , or $96 \%$ of the dgLys requirement, but not birds fed $104 \%$. The predicted dgLys requirement to maximize performance, carcass, and digestible lysine intake was 97.6 to $\geq 104 \%$. The predicted dose of phytase to maximize BWG or FCR was between 1,990 and 2,308 FTU/kg, regardless of the dgLys concentration in the diet. The predicted dose of phytase to maximize carcass weight was between 1,527 and 2,658 FTU $/ \mathrm{kg}$ of diet and to maximize breast weight was 0 to $\geq 3,000 \mathrm{FTU} / \mathrm{kg}$ diet, depending on the dgLys concentration in the diet. In conclusion, optimal performance in the absence of phytase could be achieved at much lower levels of lysine in the presence of phytase.

Key words: apparent ileal digestibility, broiler, lysine, performance, phytase

(C) The Author(s) 2018. Published by Oxford University Press on behalf of the American Society of Animal Science. All rights reserved. For permissions, please e-mail: journals.permissions@oup.com.

J. Anim. Sci. 2019.97:698-713 doi: $10.1093 /$ jas/sky441

\section{INTRODUCTION}

Lysine is an important amino acid for protein synthesis, meat yield, and growth. In poultry,

${ }^{1}$ Corresponding author: carrie.walk@abvista.com

Received May 22, 2018.

Accepted November 13, 2018. lysine is considered the second limiting amino acid (Dozier et al., 2010). The digestible lysine (dgLys) requirement of male Cobb broilers fed corn and soy diets has been recently estimated to range from 1.17 to $0.98 \%$ dgLys (using a quadratic broken line regression), depending on the response variable selected and bird age (Cemin et al., 2017). These results were in general agreement with the dgLys 
requirement of Cobb broilers estimated by others using corn, sorghum and soybean meal-based diets (Bernal et al., 2014). However, in both recent experiments, the inclusion of phytase and the impact of phytate and phytase on the dgLys requirement was not considered.

Dietary phytate has a significant and negative impact on the birds' capacity to efficiently utilize protein and amino acids from the diet. Phytate and lower phytate esters have been reported to reduce endogenous protease activity (Liu et al., 2009; Yu et al., 2012), bind proteins, peptides and free amino acids (Selle et al., 2012) and increase endogenous amino acid losses (Cowieson et al., 2008). Therefore, dietary phytate may have an impact on the predicted amino acid requirement of broilers.

Phytase supplementation is reported to improve amino acid digestibility (Cowieson and Bedford, 2009), reduce endogenous amino acid losses (Cowieson and Ravindran, 2007), and mitigate the negative effect of phytate on endogenous protease activity (Liu et al., 2009) through near complete destruction of phytate (Walk et al., 2014; Beeson et al., 2017). However, the effect of phytase on amino acid digestibility and its impact on the animals' amino acid requirement will vary with the amino acid and the dose of phytase employed. For example, the effect of phytase on the apparent ileal digestibility (AID) of lysine was 2.5\% compared with that of threonine or cysteine which were much greater at 5.0 or $4.6 \%$, respectively (Cowieson and Bedford, 2009). Therefore, the objective of this set of trials was to determine the influence of phytase dose on the dgLys requirement of broilers fed cornsoy diets using growth performance, carcass and breast meat weight, and AID of amino acids as response variables.

\section{MATERIALS AND METHODS}

All experimental procedures complied with Indian standards for the ethical use of vertebrate animals in research.

\section{Animals and Husbandry}

Experiment 1. Cobb 400 male broilers $(n=6,336)$ were obtained at the day of hatch and placed in floor pens on clean rice husk at a stocking density of $14.4 \mathrm{chicks} / \mathrm{m}^{2}$. There were $33 \mathrm{birds} / \mathrm{pen}$ and 12 replicate pens/diet. Birds were vaccinated against Newcastle Disease virus and Infectious Bursal Disease virus per label recommendations. For the entire duration of the experiment (42d), birds were maintained on a lighting program of 23L:1D and allowed ad libitum access to feed and water.

Experiment 2. Cobb 400 male broilers $(n=3,200)$ were obtained at the day of hatch and placed in floor pens on clean rice husk at a stocking density of $14.4 \mathrm{chicks} / \mathrm{m}^{2}$. There were $25 \mathrm{birds} /$ pen and 8 replicate pens/diet. Birds were vaccinated against Newcastle Disease virus and Infectious Bursal Disease virus per label recommendations. For the entire duration of the experiment ( $21 \mathrm{~d})$, birds were maintained on a lighting program of 23L:1D and allowed ad libitum access to feed and water.

\section{Dietary Treatments}

All diets were based on corn-soybean meal and fed in mash form (Tables 1 and 2). Except for $\mathrm{Ca}$ and $\mathrm{P}$, which were reduced by 0.16 and $0.15 \%$, respectively, and dgLys, diets were formulated to meet or exceed Cobb 400 requirements (VenCobb 400 Broiler Management Guide, Cobb-Vantress Inc., Siloam Spring, AR). Dietary treatments consisted of 4 levels of dgLys, 80, 88, 96, and $104 \%$ of the requirement at each feeding phase (VenCobb 400 Broiler Management Guide, Cobb-Vantress Inc., Siloam Spring, AR); this corresponds to 1.02, 1.13, 1.23 , and $1.33 \%$ dgLys, respectively, in the starter diets and $0.84,0.92,1.01$, and $1.09 \%$ dgLys, respectively, in the grower diets. Four doses of phytase $[0,750,1,500$, and 3,000 phytase units (FTU)/kg] were supplemented at each concentration of dgLys to create a $4 \times 4$ factorial arrangement of treatments. Where appropriate, phytase was added to the diets at the expense of corn to equal $100 \%$. The phytase was a modified Escherichia coli 6-phytase expressed in Trichoderma reesei with an expected activity of 5,000 FTU/g (Quantum Blue, AB Vista, Marlborough, UK). One FTU is defined as the amount of enzyme required to release $1 \mu \mathrm{mol}$ of inorganic $\mathrm{P} / \mathrm{min}$ from sodium phytate at $37^{\circ} \mathrm{C}$ and pH 5.5.

\section{Response Variables}

Experiment 1. Birds were weighed by pen prior to placement (d 0), and on d 21 and d 42 to determine mean BW and to calculate mean BW gain (BWG). Feed addition and feed remaining within each pen were measured at $\mathrm{d} 0$, feed changes ( $\mathrm{d} 21)$, and the conclusion of the trial (d 42) to calculate pen feed intake (FI). Body weight gain and FI were used to calculate feed conversion ratio (FCR). Mortality was recorded daily. Any culled or dead birds were 
Table 1. Calculated and analyzed nutrient content of the starter diets (Exps. 1 and 2)

\begin{tabular}{|c|c|c|c|c|}
\hline \multirow[b]{2}{*}{ Basal diet } & \multicolumn{4}{|c|}{ Percent digestible lysine requirement } \\
\hline & $80 \%$ & $88 \%$ & $96 \%$ & $104 \%$ \\
\hline \multicolumn{5}{|l|}{ Ingredient, $\%$ of diet (as-fed basis) } \\
\hline Corn & 60.47 & 60.28 & 60.12 & 59.97 \\
\hline Soybean meal, $48 \%$ & 31.04 & 31.07 & 31.08 & 31.10 \\
\hline Cottonseed meal, $36 \%$ & 2.50 & 2.50 & 2.50 & 2.50 \\
\hline Soybean oil & 2.25 & 2.24 & 2.24 & 2.23 \\
\hline Salt & 0.39 & 0.34 & 0.30 & 0.26 \\
\hline Limestone & 0.77 & 0.77 & 0.77 & 0.77 \\
\hline Dicalcium phosphate $^{1}$ & 1.20 & 1.20 & 1.20 & 1.20 \\
\hline Sodium bicarbonate & 0.05 & 0.12 & 0.18 & 0.24 \\
\hline Lysine- $\mathrm{HCl}$ & 0.00 & 0.14 & 0.27 & 0.40 \\
\hline DL-methionine & 0.35 & 0.35 & 0.35 & 0.35 \\
\hline Threonine & 0.13 & 0.13 & 0.13 & 0.13 \\
\hline Vitamin and mineral premix ${ }^{2}$ & 0.50 & 0.50 & 0.50 & 0.50 \\
\hline Inert (corn/phytase/chromium) ${ }^{3}$ & $0.06-0.30$ & $0.06-0.30$ & $0.06-0.30$ & $0.06-0.30$ \\
\hline \multicolumn{5}{|l|}{ Nutrient composition, $\%$ (as-fed basis) } \\
\hline Crude protein & 21.50 & 21.63 & 21.75 & 21.86 \\
\hline $\mathrm{ME}, \mathrm{kcal} / \mathrm{kg}$ & 302,500 & 302,500 & 302,500 & 302,500 \\
\hline Dry matter & 87.26 & 87.28 & 87.29 & 87.31 \\
\hline Calcium & 0.78 & 0.78 & 0.78 & 0.78 \\
\hline Total phosphorus & 0.62 & 0.62 & 0.62 & 0.62 \\
\hline Available phosphorus & 0.30 & 0.30 & 0.30 & 0.30 \\
\hline Total lysine & 1.15 & 1.26 & 1.36 & 1.46 \\
\hline Digestible lysine & 1.02 & 1.13 & 1.23 & 1.33 \\
\hline Digestible methionine + cysteine & 0.95 & 0.95 & 0.95 & 0.95 \\
\hline Digestible threonine & 0.83 & 0.83 & 0.83 & 0.83 \\
\hline Sodium & 0.18 & 0.18 & 0.18 & 0.18 \\
\hline Chloride & 0.28 & 0.28 & 0.28 & 0.28 \\
\hline \multicolumn{5}{|c|}{ Analyzed nutrient composition, $\%$ (dry matter basis) } \\
\hline \multicolumn{5}{|c|}{ Experiment 1} \\
\hline Crude protein & 24.55 & 24.30 & 24.88 & 23.68 \\
\hline Total lysine & 1.31 & 1.47 & 1.58 & 1.66 \\
\hline \multicolumn{5}{|l|}{ Experiment 2} \\
\hline Crude protein & 22.14 & 22.31 & 21.94 & 21.94 \\
\hline Total lysine & 1.17 & 1.30 & 1.33 & 1.41 \\
\hline 0 FTU/kg phytase & $<50$ & $<50$ & $<50$ & $<50$ \\
\hline 750 FTU/kg phytase & 909 & 980 & 982 & 1,010 \\
\hline 1,500 FTU/kg phytase & 2,100 & 1,920 & 1,600 & 1,700 \\
\hline 3,000 FTU/kg phytase & 3,930 & 3,770 & 3,080 & 4,180 \\
\hline
\end{tabular}

${ }^{1}$ Dicalcium phosphate supplied $18.5 \% \mathrm{P}$ and $22 \% \mathrm{Ca}$.

${ }^{2}$ Supplied per kilogram of diet: iron (ferrous sulfate), $34 \mathrm{mg}$; manganese (manganese sulfate), $38 \mathrm{mg}$; zinc (zinc sulfate), $34 \mathrm{mg}$; copper (basic copper chloride), $6 \mathrm{mg}$; iodine (calcium iodate), $0.8 \mathrm{mg}$; selenium (sodium selenite), $113 \mu \mathrm{g}$; vitamin A, $9.4 \mathrm{MIU}$; vitamin $\mathrm{D}_{3} 2.1 \mathrm{MIU}$; vitamin E, $22.5 \mathrm{mg}$; vitamin $\mathrm{B}_{12}, 11 \mu \mathrm{g}$; riboflavin, $3.8 \mathrm{mg}$; niacin, $25 \mathrm{mg}$; d-pantothenic acid, $11 \mathrm{mg}$; vitamin $\mathrm{K}, 1.5 \mathrm{mg}$; folic acid, $0.8 \mathrm{mg}$; vitamin $\mathrm{B}_{6}, 1.9 \mathrm{mg}$; thiamine, $1.5 \mathrm{mg}$; biotin, $60 \mu \mathrm{g}$.

${ }^{3}$ Corn was added in place of phytase in the diets without phytase supplementation. The phytase used was Quantum Blue (AB Vista, Marlborough, UK) with an expected activity of 5,000 FTU/g. Chromium was included in the diets of Exp. 2 at $0.30 \%$ for determination of apparent ileal amino acid digestibility at the expense of corn.

weighed. Treatment FI and subsequently FCR were adjusted according to the number of bird $\mathrm{d} /$ pen, where bird $d$ is defined as the number of days each bird survived. On d 42, 1 bird/pen of average BW was euthanized after being deprived of feed for $8 \mathrm{~h}$ and carcass, breast meat, and abdominal fat weights were obtained.
Diet DM, crude protein and amino acids were determined at Sciantec Analytical Services Ltd (Cawood, UK). Crude protein concentration in the diets was determined using the DUMAS method with a LECO FP-528 $\mathrm{N}$ analyzer and DM content was determined by gravimetry using a forced air oven at $100{ }^{\circ} \mathrm{C}$ for $24 \mathrm{~h}$. For 
Table 2. Calculated and analyzed nutrient content of the grower diets (Exp. 1)

\begin{tabular}{|c|c|c|c|c|}
\hline \multirow[b]{2}{*}{ Basal diet } & \multicolumn{4}{|c|}{ Percent digestible lysine requirement } \\
\hline & $80 \%$ & $88 \%$ & $96 \%$ & $104 \%$ \\
\hline \multicolumn{5}{|l|}{ Ingredient, $\%$ of diet (as-fed basis) } \\
\hline Corn & 63.44 & 63.59 & 63.76 & 63.91 \\
\hline Soybean meal, $48 \%$ & 23.52 & 23.27 & 22.99 & 22.74 \\
\hline Cottonseed meal, $36 \%$ & 5.00 & 5.00 & 5.00 & 5.00 \\
\hline Soybean oil & 4.64 & 4.61 & 4.56 & 4.52 \\
\hline Salt & 0.39 & 0.35 & 0.30 & 0.27 \\
\hline Limestone & 0.85 & 0.85 & 0.85 & 0.85 \\
\hline Dicalcium phosphate $^{1}$ & 0.91 & 0.91 & 0.91 & 0.91 \\
\hline Sodium bicarbonate & 0.05 & 0.12 & 0.18 & 0.23 \\
\hline Lysine- $\mathrm{HCl}$ & 0.00 & 0.11 & 0.24 & 0.35 \\
\hline DL-methionine & 0.25 & 0.26 & 0.26 & 0.26 \\
\hline Threonine & 0.08 & 0.09 & 0.09 & 0.10 \\
\hline Vitamin and mineral premix ${ }^{2}$ & 0.50 & 0.50 & 0.50 & 0.50 \\
\hline Inert (corn/phytase) $)^{3}$ & 0.06 & 0.06 & 0.06 & 0.06 \\
\hline \multicolumn{5}{|l|}{ Nutrient composition, $\%$ (as-fed basis) } \\
\hline Crude protein & 19.00 & 19.00 & 19.00 & 19.00 \\
\hline $\mathrm{ME}, \mathrm{kcal} / \mathrm{kg}$ & 320,000 & 320,000 & 320,000 & 320,000 \\
\hline Dry matter & 87.52 & 87.53 & 87.54 & 87.54 \\
\hline Calcium & 0.72 & 0.72 & 0.72 & 0.72 \\
\hline Total phosphorus & 0.55 & 0.55 & 0.55 & 0.55 \\
\hline Available phosphorus & 0.25 & 0.25 & 0.25 & 0.25 \\
\hline Total lysine & 0.96 & 1.05 & 1.14 & 1.21 \\
\hline Digestible lysine & 0.84 & 0.92 & 1.01 & 1.09 \\
\hline Digestible methionine + cysteine & 0.79 & 0.79 & 0.79 & 0.79 \\
\hline Digestible threonine & 0.69 & 0.69 & 0.69 & 0.69 \\
\hline Sodium & 0.18 & 0.18 & 0.18 & 0.18 \\
\hline Chloride & 0.28 & 0.28 & 0.28 & 0.28 \\
\hline \multicolumn{5}{|c|}{ Analyzed nutrient composition, \% (dry matter basis) } \\
\hline Crude protein & 21.05 & 20.83 & 22.38 & 21.33 \\
\hline Total lysine & 1.08 & 1.12 & 1.31 & 1.36 \\
\hline
\end{tabular}

${ }^{1}$ Dicalcium phosphate supplied $18.5 \% \mathrm{P}$ and $22 \% \mathrm{Ca}$.

${ }^{2}$ Supplied per kilogram of diet: iron (ferrous sulfate), $34 \mathrm{mg}$; manganese (manganese sulfate), $38 \mathrm{mg}$; zinc (zinc sulfate), $34 \mathrm{mg}$; copper (basic copper chloride), $6 \mathrm{mg}$; iodine (calcium iodate), $0.8 \mathrm{mg}$; selenium (sodium selenite), $113 \mu \mathrm{g}$; vitamin A, $9.4 \mathrm{MIU}$; vitamin $\mathrm{D}_{3} 2.1 \mathrm{MIU}$; vitamin E, $22.5 \mathrm{mg}$; vitamin $\mathrm{B}_{12}, 11 \mu \mathrm{g}$; riboflavin, $3.8 \mathrm{mg}$; niacin, $25 \mathrm{mg}$; d-pantothenic acid, $11 \mathrm{mg}$; vitamin $\mathrm{K}, 1.5 \mathrm{mg}$; folic acid, $0.8 \mathrm{mg}$; vitamin $\mathrm{B}_{6}$, $1.9 \mathrm{mg}$; thiamine, $1.5 \mathrm{mg}$; biotin, $60 \mu \mathrm{g}$.

${ }^{3}$ Corn was added in place of phytase in the diets without phytase supplementation. The phytase used was Quantum Blue (AB Vista, Marlborough, UK) with an expected activity of 5,000 FTU/g.

determination of amino acids, method 152/2009 of the European Commission (2009) was utilized and amino acids were separated by ion exchange chromatography.

Experiment 2. Birds were weighed by pen prior to placement ( $\mathrm{d} 0$ ) and on $\mathrm{d} 21$ to determine mean BW and to calculate mean BWG. Feed addition and feed remaining within each pen were measured at $\mathrm{d} 0$ and the conclusion of the trial (d 21) to calculate pen FI. Body weight gain and FI were used to calculate FCR. Mortality was recorded daily. Any culled or dead birds were weighed. Treatment FI and subsequently FCR were adjusted according to the number of bird $\mathrm{d} /$ pen.
On d 21, 8 birds/pen were anaesthetized by exposure to $\mathrm{CO}_{2}$ gas for approximately $30 \mathrm{~s}$ and euthanized by cervical dislocation for ileal digesta collection. Digesta was collected from the entire ileum (defined as Meckel's diverticulum to the ileocecal junction) by gently squeezing and pooled within pen for determination of AID of amino acids. Diets and digesta were dried at $70{ }^{\circ} \mathrm{C}$ in a forced air oven for $48 \mathrm{~h}$ and ground to pass a $1 \mathrm{~mm}$ screen. The use of oven drying was based on availability of equipment and the previously reported use of oven drying at $>$ $80{ }^{\circ} \mathrm{C}$ for determination of amino acid digestibility (Dale et al., 1985; Ravindran et al., 2001; Cowieson et al., 2006). Experimental diets and digesta were analyzed for amino acids (method 982.30), crude 
protein (method 984.13 A-D) and chromium (method 990.08) according to AOAC (2006) at the University of Missouri Agricultural Experiment Station (Columbia, MO). Phytase activity recovered in the diets was analyzed by Enzyme Services and Consultancy (Ystrad Mynach, UK) according to modified methods of Engelen et al. (2001).

\section{Calculations and Statistical Analyses}

Apparent ileal amino acid digestibility was calculated using chromium ratios in the diets and digesta (Ravindran et al., 1999). The equation was:

$A I D(\%)=\frac{\left[\left(\frac{A A}{C r}\right) \text { diet }-\left(\frac{A A}{C r}\right) \text { ileal }\right]}{\left(\frac{A A}{C r}\right) \text { diet }} \times 100$, where $\left(\frac{A A}{C r}\right)$ diet $=$ the ratio of amino acid to chromium in the diet; and $\left(\frac{A A}{C r}\right)$ ileal $=$ the ratio of amino acid to chromium in the ileal digesta.

In both the experiments, data were analyzed as a $4 \times 4$ factorial using the fit model platform of JMP 13.0 (SAS Institute, Cary, NC). Outliers were determined as 3 times the root mean square error plus or minus the mean of response including the suspected outlier. Plotting the growth performance, carcass, or AID data using a normal quantile plot indicated the means were normally distributed. Pen served as the experimental unit for all parameters measured, except carcass in which bird was the experimental unit. The statistical model included dietary dgLys, phytase, and the interaction. When differences were significant, means were separated using linear and quadratic orthogonal contrast statements. Significance was accepted at $P \leq 0.05$.

If the interaction or the main effects were significant, the fit model platform of JMP 13.0 (SAS Institute, Cary, NC) was used to predict the linear or non-linear effect of dgLys concentration, phytase dose, or the interaction to maximize BWG, carcass or breast meat weight, and AID of lysine, or minimize FCR. Dietary concentrations of dgLys and phytase were considered continuous, independent variables. The full model equation was: $y=a+b x+c x^{2}+b v+c v^{2}+x v$, where $y=$ response variable, $a=$ intercept, $b$ and $c=$ linear and non-linear coefficients, $x=$ calculated dgLys concentration in the experimental diet, and $v=$ expected phytase dose in the experimental diet. The parameter estimates of the model that were not significant and were not included in a significant interaction were removed from the model and the estimates were recalculated (Gonzalez-Vega et al., 2016). The maximum (or minimum for FCR) $y$ was determined using the predicted models and the profiler option in JMP.

\section{RESULTS}

The objective of the current set of trials was to determine the influence of phytase dose on the dgLys requirement of broilers. In Exp. 1, due to loss of feed samples it was not possible to analyze the phytase recoveries in the experimental diets. However, in Exp. 2, phytase recoveries in the experimental diets were within expected ranges when assay variation and product overages are considered (Table 1). Total lysine and crude protein analyzed in the diets were slightly higher (Exp. 1) or as expected (Exp. 2) and indicate graded reductions in lysine were achieved in the experimental diets (Tables 1 and 2).

\section{Animal Performance and Carcass Evaluation}

Experiment 1. Overall mortality was $2.08 \%$ and was not significantly affected by dgLys, phytase, or the interaction (data not shown). From hatch to $\mathrm{d} 21$ (Table 3) and overall (Table 4), dgLys supplementation increased (quadratic, $P<0.05$ ) FI and improved (quadratic, $P<0.05$ ) BWG, with a greatest effect occurring in the birds fed 80 to $88 \%$ of the dgLys requirement (1.02 to $1.13 \%$ dgLys in the starter phase and 0.84 to $0.92 \%$ dgLys in the grower phase). There was no effect of phytase supplementation on FI from hatch to day 21 or overall. Phytase supplementation improved (quadratic, $P<0.05$ ) BWG, with the greatest response between 750 and 3,000 FTU/kg, regardless of the dgLys concentration in the diet. From hatch to day 21, FCR was improved (quadratic, $P<0.05$ ) with phytase supplementation at each concentration of dgLys; with birds fed 80 or 96\% (1.02 or $1.23 \%$ dgLys), $88 \%$ (1.13\% dgLys), or $104 \%(1.33 \%$ dgLys $)$ of the dgLys requirement having the lowest FCR at 1,500, 750, or 3,000 FTU/kg of phytase, respectively (dgLys $\times$ phytase, $P<0.05)$. Overall (hatch to day 42), phytase supplementation from 0 to 3,000 FTU/kg quadratically $(P<0.05)$ improved FCR in birds fed 80 or $88 \%$ of the dgLys requirement $(1.02$ or $1.13 \%$ dgLys in the starter diets and 0.84 or $0.92 \%$ dgLys in the grower diets) and linearly $(P<0.05)$ improved FCR in birds fed 96 to $104 \%$ of the dgLys requirement $(1.23$ or $1.33 \%$ dgLys in the starter diets and 1.01 or $1.09 \%$ dgLys in the grower diets) (dgLys $\times$ phytase, $P<0.05)$. 


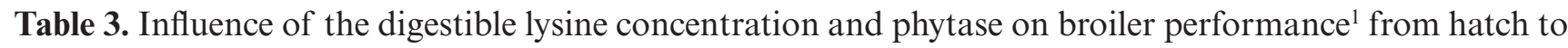
21 d posthatch (Exp. 1)

\begin{tabular}{|c|c|c|c|c|}
\hline$\%$ of the digestible Lys requirement & Phytase, FTU/kg & Feed intake, $\mathrm{g}$ & BW gain, $\mathrm{g}$ & FCR, g:g \\
\hline \multirow[t]{4}{*}{80} & 0 & 1,150 & 816 & 1.411 \\
\hline & 750 & 1,133 & 824 & 1.376 \\
\hline & 1,500 & 1,155 & 849 & 1.361 \\
\hline & 3,000 & 1,162 & 848 & 1.370 \\
\hline \multirow[t]{4}{*}{88} & 0 & 1,205 & 911 & 1.324 \\
\hline & 750 & 1,205 & 937 & 1.286 \\
\hline & 1,500 & 1,190 & 914 & 1.302 \\
\hline & 3,000 & 1,190 & 910 & 1.303 \\
\hline \multirow[t]{4}{*}{96} & 0 & 1,206 & 926 & 1.303 \\
\hline & 750 & 1,220 & 960 & 1.272 \\
\hline & 1,500 & 1,182 & 933 & 1.268 \\
\hline & 3,000 & 1,210 & 953 & 1.269 \\
\hline \multirow[t]{4}{*}{104} & 0 & 1,206 & 913 & 1.321 \\
\hline & 750 & 1,209 & 959 & 1.262 \\
\hline & 1,500 & 1,218 & 957 & 1.274 \\
\hline & 3,000 & 1,205 & 957 & 1.258 \\
\hline SEM & & 11 & 10 & 0.005 \\
\hline dgLys $\times$ phytase & & 0.1876 & 0.0689 & 0.0004 \\
\hline \multirow[t]{2}{*}{$80 \%$ dgLys } & Linear phytase & & & $<0.0001$ \\
\hline & Quadratic phytase & & & $<0.0001$ \\
\hline \multirow[t]{2}{*}{$88 \%$ dgLys } & Linear phytase & & & 0.1105 \\
\hline & Quadratic phytase & & & 0.0002 \\
\hline \multirow[t]{2}{*}{$96 \%$ dgLys } & Linear phytase & & & $<0.0001$ \\
\hline & Quadratic phytase & & & $<0.0001$ \\
\hline \multirow[t]{2}{*}{$104 \%$ dgLys } & Linear phytase & & & $<0.0001$ \\
\hline & Quadratic phytase & & & $<0.0001$ \\
\hline 80 & & 1,150 & 834 & 1.379 \\
\hline 88 & & 1,197 & 918 & 1.303 \\
\hline 96 & & 1,205 & 943 & 1.278 \\
\hline 104 & & 1,210 & 947 & 1.279 \\
\hline SEM & & 5 & 5 & 0.002 \\
\hline dgLys & & $<0.0001$ & $<0.0001$ & $<0.0001$ \\
\hline Linear & & $<0.0001$ & $<0.0001$ & $<0.0001$ \\
\hline \multirow[t]{5}{*}{ Quadratic } & & 0.0001 & $<0.0001$ & $<0.0001$ \\
\hline & 0 & 1,192 & 891 & 1.340 \\
\hline & 750 & 1,192 & 920 & 1.299 \\
\hline & 1,500 & 1,186 & 913 & 1.301 \\
\hline & 3,000 & 1,191 & 917 & 1.300 \\
\hline SEM & & 5 & 5 & 0.002 \\
\hline Phytase & & 0.8716 & 0.0002 & $<0.0001$ \\
\hline Linear & & & 0.0045 & $<0.0001$ \\
\hline Quadratic & & & 0.0147 & $<0.0001$ \\
\hline
\end{tabular}

${ }^{1}$ Means represent the average response of 12 replicate pens/treatment and 33 birds/pen.

Carcass weight increased linearly or quadratically $(P<0.05)$ as phytase supplementation increased in the diet of birds fed 80 or $96 \%$, respectively, of the dgLys requirement (1.02 or $1.23 \%$ dgLys in the starter diets and 0.84 or $1.01 \%$ dgLys in the grower diets), whereas there was no effect of phytase on carcass weight of birds fed 88 or $104 \%$ of the dgLys requirement ( 1.13 or $1.33 \%$ dgLys in the starter diets and 0.92 or $1.09 \%$ dgLys in the grower diets) $($ dgLys $\times$ phytase, $P<0.05$; Table 5). Breast meat weight (linear, $P<0.05$ ) and breast meat yield as a percent of carcass weight (quadratic, $P<0.05$ ) increased and fat pad weight and yield, as a percent of carcass weight, decreased (linear, $P<0.05$ ) as dgLys supplementation increased in the diet from 80 to $104 \%$ of the requirement (1.02 to $1.33 \%$ dgLys in the starter diets and 0.84 to $1.09 \%$ in the grower diets) (Table 5). Phytase supplementation 
Table 4. Influence of the digestible lysine concentration and phytase on broiler performance ${ }^{1}$ from hatch to $42 \mathrm{~d}$ posthatch (Exp. 1)

\begin{tabular}{|c|c|c|c|c|}
\hline$\%$ of the digestible Lys requirement & Phytase, FTU/kg & Feed intake, $g$ & BW gain, $\mathrm{g}$ & FCR, g:g \\
\hline \multirow[t]{4}{*}{80} & 0 & 4,067 & 2,343 & 1.736 \\
\hline & 750 & 4,067 & 2,402 & 1.693 \\
\hline & 1,500 & 4,072 & 2,414 & 1.687 \\
\hline & 3,000 & 4,108 & 2,439 & 1.684 \\
\hline \multirow[t]{4}{*}{88} & 0 & 4,145 & 2,488 & 1.666 \\
\hline & 750 & 4,182 & 2,553 & 1.638 \\
\hline & 1,500 & 4,090 & 2,524 & 1.632 \\
\hline & 3,000 & 4,135 & 2,522 & 1.639 \\
\hline \multirow[t]{4}{*}{96} & 0 & 4,157 & 2,513 & 1.654 \\
\hline & 750 & 4,152 & 2,562 & 1.630 \\
\hline & 1,500 & 4,128 & 2,547 & 1.621 \\
\hline & 3,000 & 4,125 & 2,576 & 1.601 \\
\hline \multirow[t]{4}{*}{104} & 0 & 4,128 & 2,508 & 1.647 \\
\hline & 750 & 4,123 & 2,556 & 1.613 \\
\hline & 1,500 & 4,193 & 2,580 & 1.631 \\
\hline & 3,000 & 4,128 & 2,556 & 1.616 \\
\hline SEM & & 27 & 16 & 0.006 \\
\hline dgLys $\times$ phytase & & 0.1524 & 0.3758 & 0.0427 \\
\hline \multirow[t]{2}{*}{$80 \%$ dgLys } & Linear phytase & & & $<0.0001$ \\
\hline & Quadratic phytase & & & 0.0021 \\
\hline \multirow[t]{2}{*}{$88 \%$ dgLys } & Linear phytase & & & 0.0026 \\
\hline & Quadratic phytase & & & 0.0046 \\
\hline \multirow[t]{2}{*}{$96 \%$ dgLys } & Linear phytase & & & $<0.0001$ \\
\hline & Quadratic phytase & & & 0.7133 \\
\hline \multirow[t]{2}{*}{$104 \%$ dgLys } & Linear phytase & & & 0.0251 \\
\hline & Quadratic phytase & & & 0.1415 \\
\hline 80 & & 4,078 & 2,400 & 1.700 \\
\hline 88 & & 4,138 & 2,522 & 1.644 \\
\hline 96 & & 4,140 & 2,550 & 1.626 \\
\hline 104 & & 4,143 & 2,550 & 1.626 \\
\hline SEM & & 13 & 8 & 0.003 \\
\hline dgLys & & 0.0011 & $<0.0001$ & $<0.0001$ \\
\hline Linear & & 0.0018 & $<0.0001$ & $<0.0001$ \\
\hline \multirow[t]{5}{*}{ Quadratic } & & 0.0330 & $<0.0001$ & $<0.0001$ \\
\hline & 0 & 4,124 & 2,463 & 1.676 \\
\hline & 750 & 4,131 & 2,518 & 1.643 \\
\hline & 1,500 & 4,121 & 2,516 & 1.643 \\
\hline & 3,000 & 4,124 & 2,524 & 1.635 \\
\hline SEM & & 13 & 8 & 0.003 \\
\hline Phytase & & 0.9567 & $<0.0001$ & $<0.0001$ \\
\hline Linear & & & $<0.0001$ & $<0.0001$ \\
\hline Quadratic & & & 0.0026 & 0.0001 \\
\hline
\end{tabular}

${ }^{1}$ Means represent the average response of 12 replicate pens/treatment and 33 birds/pen.

from 0 to 3,000 FTU/kg increased (linear, $P<0.05$ ) breast meat weight (Table 5). There was no effect of phytase supplementation on fat pad weight, or fat pad yield or breast meat yield as a percent of carcass weight. Carcass yield as a percent of live weight was not influenced by dgLys, phytase, or the interaction (data not shown).

Experiment 2. Overall mortality was $0.56 \%$ and not significantly affected by dgLys, phytase, or the interaction (data not shown). From hatch to $\mathrm{d} 21$, increasing the concentration of dgLys in the diet from 80 to $104 \%$ of the requirement (1.02 to $1.33 \%$ dgLys) increased (linear, $P<0.05$ ) FI and improved (quadratic, $P<0.05$ ) BWG and FCR, with the greatest improvements noted between 80 and $96 \%$ (for FCR) of the requirement (1.02 to $1.23 \%$ dgLys) (Table 6). There was no effect of phytase supplementation on FI. However, BWG and FCR were improved (quadratic, $P<0.05$ ) as 
Table 5. Influence of the digestible lysine concentration and phytase on broiler carcass weight and percent ${ }^{1}$ at $42 \mathrm{~d}$ posthatch (Exp. 1)

\begin{tabular}{|c|c|c|c|c|c|c|}
\hline $\begin{array}{l}\% \text { of the digestible Lys } \\
\text { requirement }\end{array}$ & Phytase & Carcass, $\mathrm{g}$ & Breast, $\mathrm{g}$ & Fat, $\mathrm{g}$ & Breast, $\%$ carcass & Fat, $\%$ carcass \\
\hline \multirow[t]{4}{*}{80} & 0 & 2,154 & 636 & 55.4 & 29.4 & 2.58 \\
\hline & 750 & 2,144 & 638 & 48.5 & 29.8 & 1.93 \\
\hline & 1,500 & 2,192 & 664 & 56.4 & 30.2 & 2.11 \\
\hline & 3,000 & 2,360 & 749 & 53.2 & 31.8 & 2.11 \\
\hline \multirow[t]{4}{*}{88} & 0 & 2,149 & 680 & 41.5 & 31.6 & 2.26 \\
\hline & 750 & 2,317 & 764 & 49.7 & 33.0 & 2.14 \\
\hline & 1,500 & 2,308 & 734 & 52.9 & 31.7 & 2.00 \\
\hline & 3,000 & 2,283 & 728 & 50.6 & 31.8 & 1.74 \\
\hline \multirow[t]{4}{*}{96} & 0 & 2,196 & 700 & 46.3 & 31.8 & 2.56 \\
\hline & 750 & 2,370 & 776 & 47.5 & 32.7 & 2.29 \\
\hline & 1,500 & 2,324 & 761 & 47.7 & 32.7 & 2.04 \\
\hline & 3,000 & 2,289 & 756 & 44.3 & 33.0 & 2.22 \\
\hline \multirow[t]{4}{*}{104} & 0 & 2,275 & 744 & 48.4 & 32.7 & 2.26 \\
\hline & 750 & 2,300 & 755 & 39.8 & 32.8 & 2.22 \\
\hline & 1,500 & 2,410 & 786 & 50.8 & 32.6 & 1.95 \\
\hline & 3,000 & 2,280 & 749 & 44.5 & 32.8 & 1.95 \\
\hline SEM & & 49 & 23 & 3.5 & 0.6 & 0.1 \\
\hline dgLys $\times$ phytase & & 0.0433 & 0.0594 & 0.3786 & 0.4850 & 0.4863 \\
\hline \multirow[t]{2}{*}{$80 \%$ dgLys } & Linear phytase & 0.0033 & & & & \\
\hline & Quadratic phytase & 0.0683 & & & & \\
\hline \multirow[t]{2}{*}{$88 \%$ dgLys } & Linear phytase & 0.0946 & & & & \\
\hline & Quadratic phytase & 0.0513 & & & & \\
\hline \multirow[t]{2}{*}{$96 \%$ dgLys } & Linear phytase & 0.3631 & & & & \\
\hline & Quadratic phytase & 0.0346 & & & & \\
\hline \multirow[t]{2}{*}{$104 \%$ dgLys } & Linear phytase & 0.4349 & & & & \\
\hline & Quadratic phytase & 0.1164 & & & & \\
\hline 80 & & 2,212 & 672 & 53.4 & 30.3 & 2.42 \\
\hline 88 & & 2,264 & 727 & 48.7 & 32.0 & 2.14 \\
\hline 96 & & 2,295 & 748 & 46.4 & 32.6 & 2.02 \\
\hline 104 & & 2,316 & 758 & 45.9 & 32.7 & 2.00 \\
\hline SEM & & 24 & 12 & 1.8 & 0.3 & 0.1 \\
\hline dgLys & & 0.0186 & $<0.0001$ & 0.0115 & $<0.0001$ & 0.0002 \\
\hline Linear & & 0.0024 & $<0.0001$ & 0.0023 & $<0.0001$ & 0.0001 \\
\hline \multirow[t]{5}{*}{ Quadratic } & & 0.5388 & 0.0614 & 0.2405 & 0.0124 & 0.0862 \\
\hline & 0 & 2,193 & 690 & 47.9 & 31.4 & 2.19 \\
\hline & 750 & 2,283 & 733 & 46.4 & 32.1 & 2.03 \\
\hline & 1,500 & 2,309 & 736 & 52.0 & 31.8 & 2.28 \\
\hline & 3,000 & 2,303 & 746 & 48.2 & 32.3 & 2.09 \\
\hline SEM & & 24 & 12 & 1.8 & 0.3 & 0.1 \\
\hline Phytase & & 0.0030 & 0.0044 & 0.1498 & 0.1674 & 0.0996 \\
\hline Linear & & 0.0018 & 0.0022 & & & \\
\hline Quadratic & & 0.0548 & 0.1538 & & & \\
\hline
\end{tabular}

${ }^{1}$ Means represent the average response of 12 birds/treatment.

phytase supplementation increased in the diet from 0 to $750 \mathrm{FTU} / \mathrm{kg}$. There was no effect of dgLys $\times$ phytase on growth performance from hatch to $\mathrm{d} 21$.

\section{Apparent Ileal Digestibility}

The influence of dgLys, phytase, and the interaction on the AID of essential or nonessential amino acids is presented in Tables 7 and 8, respectively.
The AID of threonine or valine increased (linear, $P<0.05$ ) or serine or cysteine increased (quadratic, $P<0.05$ ) as phytase dose increased from 0 to $3,000 \mathrm{FTU} / \mathrm{kg}$. The AID of methionine increased (quadratic, $P<0.05$ ) as phytase supplementation increased from 0 to 1,500 or $3,000 \mathrm{FTU} / \mathrm{kg}$, but only in the diets formulated to contain 80 or $104 \%$ of the dgLys requirement (1.02 to $1.33 \%$ dgLys) (dgLys $\times$ phytase, $P<0.05)$. The AID of 
Table 6. Influence of the digestible lysine concentration and phytase on broiler performance ${ }^{1}$ from hatch to $21 \mathrm{~d}$ posthatch (Exp. 2)

\begin{tabular}{|c|c|c|c|c|}
\hline$\%$ of the digestible Lys requirement & Phytase, FTU/kg & Feed intake, $g$ & BW gain, $g$ & FCR, g:g \\
\hline \multirow[t]{4}{*}{80} & 0 & 1,104 & 763 & 1.447 \\
\hline & 750 & 1,137 & 818 & 1.390 \\
\hline & 1,500 & 1,140 & 824 & 1.384 \\
\hline & 3,000 & 1,155 & 835 & 1.384 \\
\hline \multirow[t]{4}{*}{88} & 0 & 1,184 & 837 & 1.413 \\
\hline & 750 & 1,192 & 876 & 1.360 \\
\hline & 1,500 & 1,116 & 816 & 1.368 \\
\hline & 3,000 & 1,166 & 858 & 1.360 \\
\hline \multirow[t]{4}{*}{96} & 0 & 1,167 & 852 & 1.371 \\
\hline & 750 & 1,188 & 908 & 1.310 \\
\hline & 1,500 & 1,196 & 918 & 1.303 \\
\hline & 3,000 & 1,169 & 885 & 1.322 \\
\hline \multirow[t]{4}{*}{104} & 0 & 1,176 & 855 & 1.376 \\
\hline & 750 & 1,195 & 915 & 1.306 \\
\hline & 1,500 & 1,165 & 884 & 1.317 \\
\hline & 3,000 & 1,206 & 919 & 1.313 \\
\hline SEM & & 21 & 16 & 0.005 \\
\hline dgLys $\times$ phytase & & 0.2728 & 0.0975 & 0.1877 \\
\hline 80 & & 1,134 & 810 & 1.401 \\
\hline 88 & & 1,165 & 847 & 1.375 \\
\hline 96 & & 1,180 & 890 & 1.326 \\
\hline 104 & & 1,185 & 893 & 1.328 \\
\hline SEM & & 10 & 8 & 0.003 \\
\hline dgLys & & 0.0027 & $<0.0001$ & $<0.0001$ \\
\hline Linear & & 0.0004 & $<0.0001$ & $<0.0001$ \\
\hline \multirow[t]{5}{*}{ Quadratic } & & 0.2311 & 0.0304 & $<0.0001$ \\
\hline & 0 & 1,158 & 827 & 1.402 \\
\hline & 750 & 1,178 & 879 & 1.341 \\
\hline & 1,500 & 1,154 & 860 & 1.343 \\
\hline & 3,000 & 1,174 & 874 & 1.345 \\
\hline SEM & & 10 & 8 & 0.003 \\
\hline Phytase & & 0.2782 & $<0.0001$ & $<0.0001$ \\
\hline Linear & & & 0.0026 & $<0.0001$ \\
\hline Quadratic & & & 0.0140 & $<0.0001$ \\
\hline
\end{tabular}

${ }^{1}$ Means represent the average response of 8 replicate pens/treatment and 25 birds/pen.

isoleucine, phenylalanine, lysine, histidine, aspartate, glutamate, proline, glycine, alanine or tyrosine increased in birds fed diets containing 80\% $(1.02 \%$ dgLys) (quadratic, $P<0.05), 88 \%(1.13 \%$ dgLys) (linear, $P<0.05)$, or $96 \%(1.23 \%$ dgLys) (linear or quadratic, depending on amino acid, $P<0.05)$ of the dgLys requirement as phytase supplementation in the diet increased from 0 to $3,000 \mathrm{FTU} / \mathrm{kg}$. There was no effect of phytase supplementation on the AID of isoleucine, phenylalanine, lysine, histidine, aspartate, glutamate, proline, glycine, or alanine in birds fed $104 \%$ (1.33\% dgLys) of the dgLys requirement, which resulted in a dgLys $\times$ phytase interaction $(P<0.05)$. The AID of arginine was not influenced by dgLys or phytase, except in birds fed $88 \%$ (1.13\% dgLys) of the dgLys requirement, whereas phytase supplementation increase (linear,
$P<0.05)$ the AID of arginine; this resulted in a dgLys $\times$ phytase interaction $(P<0.05)$. There was no effect of dgLys, phytase, or the interaction on the AID of leucine or tryptophan.

\section{Regression Estimates}

In Exp. 1, the predicted dgLys requirement to maximize BWG, FI, or FCR of broilers from hatch to d 21 was 99.3 (1.24\% dgLys), 98.9 (1.24\% dgLys), or $98.9 \%$ (1.24\% dgLys), respectively, of Cobb 400 recommendations (Table 9). Phytase supplementation at 2,065 FTU/kg was predicted to maximize BWG and 2,038 FTU/kg was predicted to minimize FCR. From hatch to $\mathrm{d} 42$, the predicted dgLys requirement to maximize $\mathrm{BWG}$, FI or FCR was $98.2 \%(1.23 \%$ dgLys in the starter diet and $1.03 \%$ 
Table 7. Influence of the digestible lysine concentration and phytase on apparent ileal essential amino acid digestibility $^{1}$ of broilers at $21 \mathrm{~d}$ posthatch (Exp. 2)

\begin{tabular}{|c|c|c|c|c|c|c|c|c|c|c|c|}
\hline $\begin{array}{l}\% \text { of the } \\
\text { digestible Lys } \\
\text { requirement }\end{array}$ & $\begin{array}{l}\text { Phytase, } \\
\text { FTU/kg }\end{array}$ & $\frac{\mathrm{Thr}^{\dagger}}{\%}$ & $\frac{\mathrm{Val}^{\dagger}{ }^{\dagger}}{\%}$ & $\begin{array}{c}\text { Met, } \\
\% \\
\end{array}$ & $\begin{array}{c}\text { Iso, } \\
\% \\
\end{array}$ & $\frac{\text { Leu, }}{\%}$ & $\begin{array}{c}\text { Phe, } \\
\%\end{array}$ & $\begin{array}{c}\text { Lys, } \\
\% \\
\end{array}$ & $\begin{array}{c}\text { His, } \\
\% \\
\end{array}$ & $\frac{\operatorname{Arg},}{\%}$ & $\begin{array}{r}\text { Trp, } \\
\%\end{array}$ \\
\hline \multirow[t]{4}{*}{80} & 0 & 77.0 & 78.6 & 93.9 & 84.3 & 87.2 & 87.8 & 90.3 & 85.4 & 92.5 & 92.5 \\
\hline & 750 & 81.2 & 81.4 & 95.2 & 87.2 & 89.1 & 89.2 & 92.2 & 89.1 & 93.6 & 94.5 \\
\hline & 1,500 & 81.2 & 81.3 & 95.4 & 86.3 & 87.9 & 88.3 & 91.4 & 88.0 & 92.6 & 93.9 \\
\hline & 3,000 & 79.2 & 79.8 & 93.5 & 84.7 & 86.9 & 87.2 & 89.4 & 86.6 & 91.3 & 93.9 \\
\hline \multirow[t]{4}{*}{88} & 0 & 79.0 & 78.7 & 94.5 & 83.9 & 86.1 & 86.6 & 90.1 & 85.7 & 91.9 & 93.1 \\
\hline & 750 & 78.9 & 79.3 & 94.7 & 84.3 & 86.2 & 87.1 & 89.2 & 86.8 & 91.1 & 93.2 \\
\hline & 1,500 & 81.5 & 82.1 & 95.3 & 87.1 & 88.4 & 88.9 & 93.1 & 89.0 & 93.6 & 95.2 \\
\hline & 3,000 & 80.9 & 81.2 & 94.8 & 86.4 & 88.0 & 88.5 & 92.7 & 89.2 & 92.7 & 94.9 \\
\hline \multirow[t]{4}{*}{96} & 0 & 78.4 & 78.4 & 94.8 & 84.3 & 86.7 & 87.0 & 91.9 & 86.0 & 91.5 & 93.1 \\
\hline & 750 & 78.8 & 78.7 & 94.2 & 84.9 & 87.7 & 87.7 & 90.6 & 86.7 & 91.2 & 93.2 \\
\hline & 1,500 & 81.8 & 81.4 & 95.4 & 86.4 & 88.7 & 88.8 & 92.6 & 88.5 & 92.5 & 94.9 \\
\hline & 3,000 & 81.0 & 80.6 & 95.2 & 86.2 & 88.4 & 89.0 & 92.6 & 88.1 & 92.6 & 95.0 \\
\hline \multirow[t]{4}{*}{104} & 0 & 79.1 & 79.1 & 94.9 & 85.1 & 87.6 & 87.5 & 93.0 & 86.8 & 91.9 & 94.3 \\
\hline & 750 & 79.2 & 78.9 & 94.3 & 84.7 & 87.3 & 87.4 & 92.1 & 87.3 & 91.4 & 94.3 \\
\hline & 1,500 & 78.4 & 78.4 & 94.2 & 84.4 & 86.7 & 87.1 & 91.7 & 86.3 & 90.7 & 93.6 \\
\hline & 3,000 & 80.5 & 80.7 & 95.4 & 86.3 & 88.1 & 88.8 & 92.6 & 88.6 & 92.4 & 93.2 \\
\hline SEM & & 1.0 & 0.8 & 0.4 & 0.7 & 0.7 & 0.6 & 0.7 & 0.7 & 0.6 & 0.7 \\
\hline dgLys & & 0.6531 & 0.2372 & 0.4361 & 0.8009 & 0.4508 & 0.6773 & 0.0128 & 0.8162 & 0.1762 & 0.8531 \\
\hline Phytase & & 0.0032 & 0.0015 & 0.1588 & 0.0070 & 0.1453 & 0.0542 & 0.0782 & 0.0003 & 0.5962 & 0.0913 \\
\hline dgLys $\times$ phytase & & 0.0838 & 0.0699 & 0.0008 & 0.0104 & 0.0602 & 0.0453 & 0.0004 & 0.0129 & 0.0101 & 0.1439 \\
\hline \multirow[t]{2}{*}{$80 \%$ dgLys } & $\begin{array}{l}\text { Linear } \\
\text { phytase }\end{array}$ & & & 0.6482 & 0.9614 & & 0.3109 & 0.2688 & 0.5791 & 0.0876 & \\
\hline & $\begin{array}{l}\text { Quadratic } \\
\text { phytase }\end{array}$ & & & $<0.001$ & 0.0026 & & 0.0458 & 0.0085 & 0.0008 & 0.0620 & \\
\hline \multirow[t]{2}{*}{$88 \%$ dgLys } & $\begin{array}{l}\text { Linear } \\
\text { phytase }\end{array}$ & & & 0.3756 & 0.0007 & & 0.0062 & $<0.001$ & 0.0002 & 0.0360 & \\
\hline & $\begin{array}{c}\text { Quadratic } \\
\text { phytase }\end{array}$ & & & 0.3471 & 0.4656 & & 0.4585 & 0.7298 & 0.5257 & 0.9860 & \\
\hline \multirow[t]{2}{*}{$96 \%$ dgLys } & $\begin{array}{l}\text { Linear } \\
\text { phytase }\end{array}$ & & & 0.0899 & 0.0201 & & 0.0111 & 0.1302 & 0.0137 & 0.0706 & \\
\hline & $\begin{array}{r}\text { Quadratic } \\
\text { phytase }\end{array}$ & & & 0.5962 & 0.5728 & & 0.7024 & 0.3523 & 0.4579 & 0.7552 & \\
\hline \multirow[t]{2}{*}{ 104\% dgLys } & $\begin{array}{l}\text { Linear } \\
\text { phytase }\end{array}$ & & & 0.3691 & 0.3470 & & 0.2563 & 0.6245 & 0.2878 & 0.8930 & \\
\hline & $\begin{array}{r}\text { Quadratic } \\
\text { phytase }\end{array}$ & & & 0.0144 & 0.0941 & & 0.1418 & 0.1904 & 0.2197 & 0.0753 & \\
\hline
\end{tabular}

${ }^{1}$ Means represent the average response of 8 replicate pens/treatment and 8 birds/pen.

Linear main effect of phytase $(P<0.05)$.

dgLys in the grower diet), $97.6 \%(1.22 \%$ dgLys in the starter diet and $1.02 \%$ dgLys in the grower diet), or $98.9 \%$ (1.24\% dgLys in the starter diet and $1.04 \%$ dgLys in the grower diet) of Cobb 400 recommendations, respectively. Phytase supplementation at 2,146 FTU/kg was predicted to maximize BWG (Fig. 1) and 2,308 FTU/kg was predicted to minimize FCR (Fig. 2). The predicted dgLys requirement to maximize carcass or breast meat weight was different depending on the dgLys concentration in the diet and phytase dose (Table 9). For example, in the absence of phytase or with the addition of 750 or $1,500 \mathrm{FTU} / \mathrm{kg}$ of phytase, carcass weight
(Fig. 3) or breast meat weight (Fig. 4) increased as the dgLys concentration in the diet increased from 80 to $104 \%$ of the requirement (1.02 to $1.33 \%$ dgLys in the starter and 0.84 to $1.09 \%$ dgLys in the grower). However, in the presence of 3,000 FTU/ $\mathrm{kg}$ of phytase, there was no effect or only a small effect of dgLys concentration in the diet on carcass or breast meat weight.

In Exp. 2, the predicted dgLys requirement to maximize BWG, FCR, or the AID of lysine (Table 9) in broilers from hatch to $\mathrm{d} 21$ was $>104 \%$ of the requirement $(>1.33 \%$ dgLys). Phytase supplementation at $2,130 \mathrm{FTU} / \mathrm{kg}$ was predicted to 
Table 8. Influence of the digestible lysine concentration and phytase on apparent ileal nonessential amino acid digestibility ${ }^{1}$ of broilers at $21 \mathrm{~d}$ posthatch (Exp. 2)

\begin{tabular}{|c|c|c|c|c|c|c|c|c|c|}
\hline $\begin{array}{l}\% \text { of the } \\
\text { digestible Lys } \\
\text { requirement }\end{array}$ & $\begin{array}{l}\text { Phytase, } \\
\text { FTU/kg }\end{array}$ & $\frac{\text { Asp, }}{\%}$ & $\frac{\text { Ser, }}{\%}$ & $\frac{\text { Glu, }}{\%}$ & $\frac{\text { Pro, }}{\%}$ & $\frac{\text { Gly, }}{\%}$ & $\frac{\text { Ala, }}{\%}$ & $\frac{\text { Cys, }{ }^{\ddagger}}{\%}$ & $\frac{\mathrm{Tyr},}{\%}$ \\
\hline \multirow[t]{4}{*}{80} & 0 & 82.3 & 81.6 & 87.5 & 79.1 & 75.7 & 81.4 & 73.7 & 85.9 \\
\hline & 750 & 86.9 & 86.0 & 90.4 & 84.1 & 80.4 & 85.1 & 78.2 & 88.1 \\
\hline & 1,500 & 86.3 & 85.6 & 90.0 & 83.6 & 80.2 & 84.7 & 76.8 & 87.0 \\
\hline & 3,000 & 84.6 & 84.0 & 88.4 & 81.8 & 77.3 & 82.2 & 74.9 & 85.9 \\
\hline \multirow[t]{4}{*}{88} & 0 & 83.6 & 83.0 & 87.8 & 80.5 & 77.6 & 81.4 & 71.9 & 85.4 \\
\hline & 750 & 84.6 & 83.3 & 88.5 & 81.6 & 78.0 & 81.6 & 77.3 & 86.3 \\
\hline & 1,500 & 87.4 & 86.3 & 90.1 & 83.9 & 80.9 & 85.4 & 77.3 & 87.9 \\
\hline & 3,000 & 86.0 & 84.8 & 89.5 & 83.6 & 80.5 & 85.2 & 76.9 & 87.9 \\
\hline \multirow[t]{4}{*}{96} & 0 & 83.3 & 82.7 & 87.2 & 79.9 & 76.4 & 81.6 & 71.9 & 84.7 \\
\hline & 750 & 84.3 & 83.7 & 89.0 & 82.8 & 77.6 & 82.7 & 76.7 & 87.4 \\
\hline & 1,500 & 85.8 & 86.1 & 89.8 & 83.8 & 79.5 & 84.5 & 78.1 & 88.5 \\
\hline & 3,000 & 86.0 & 84.8 & 89.6 & 83.8 & 79.9 & 84.2 & 77.9 & 87.7 \\
\hline \multirow[t]{4}{*}{104} & 0 & 84.4 & 83.2 & 88.4 & 81.8 & 77.6 & 83.0 & 73.7 & 86.5 \\
\hline & 750 & 84.5 & 84.2 & 88.4 & 81.7 & 77.8 & 82.2 & 76.3 & 85.9 \\
\hline & 1,500 & 83.5 & 83.2 & 88.1 & 81.0 & 76.3 & 81.8 & 75.4 & 83.7 \\
\hline & 3,000 & 86.1 & 84.2 & 89.8 & 82.6 & 79.4 & 84.1 & 76.4 & 87.1 \\
\hline SEM & & 0.8 & 0.8 & 0.5 & 0.8 & 0.9 & 0.8 & 1.0 & 0.8 \\
\hline dgLys & & 0.5539 & 0.6240 & 0.7798 & 0.5242 & 0.1573 & 0.6671 & 0.7969 & 0.1206 \\
\hline Phytase & & $<0.001$ & 0.0002 & $<0.001$ & $<0.001$ & 0.0004 & 0.0003 & $<0.001$ & 0.0364 \\
\hline dgLys $\times$ phytase & & 0.0038 & 0.0783 & 0.0044 & 0.0116 & 0.0030 & 0.0007 & 0.2296 & 0.0023 \\
\hline \multirow[t]{2}{*}{$80 \%$ dgLys } & Linear phytase & 0.0968 & & 0.4330 & 0.0644 & 0.3059 & 0.6782 & & 0.6520 \\
\hline & $\begin{array}{c}\text { Quadratic } \\
\text { phytase }\end{array}$ & 0.0001 & & 0.0001 & 0.0001 & $<0.001$ & 0.0002 & & 0.0413 \\
\hline \multirow[t]{2}{*}{$88 \%$ dgLys } & Linear phytase & 0.0022 & & 0.0025 & 0.0012 & 0.0028 & $<0.001$ & & 0.0097 \\
\hline & $\begin{array}{l}\text { Quadratic } \\
\text { phytase }\end{array}$ & 0.1186 & & 0.2013 & 0.4092 & 0.5861 & 0.7915 & & 0.5521 \\
\hline \multirow[t]{2}{*}{$96 \%$ dgLys } & Linear phytase & 0.0049 & & 0.0007 & 0.0009 & 0.0021 & 0.0056 & & 0.0047 \\
\hline & $\begin{array}{l}\text { Quadratic } \\
\text { phytase }\end{array}$ & 0.6190 & & 0.0503 & 0.0713 & 0.6669 & 0.3970 & & 0.0275 \\
\hline \multirow[t]{2}{*}{$104 \%$ dgLys } & Linear phytase & 0.3367 & & 0.1238 & 0.7573 & 0.4604 & 0.4565 & & 0.7201 \\
\hline & $\begin{array}{r}\text { Quadratic } \\
\text { phytase }\end{array}$ & 0.1013 & & 0.0907 & 0.2771 & 0.1023 & 0.0543 & & 0.0114 \\
\hline
\end{tabular}

${ }^{1}$ Means represent the average response of 8 replicate pens/treatment and 8 birds/pen.

Quadratic main effect of phytase $(P<0.05)$.

maximize BWG and 1,990 FTU/kg was predicted to minimize FCR (Table 9).

\section{DISCUSSION}

The performance, carcass, and amino acid digestibility results indicate that the graded concentrations of dgLys in the diets were sufficient to elicit a dose response and allow for the prediction of the dgLys requirement of broilers from hatch to $\mathrm{d} 42$ (Exp. 1) and hatch to d 21 (Exp. 2), without and with phytase. In both the experiments, FI, BWG, and FCR were influenced by graded concentrations of dgLys in the diet in a quadratic manner and this has been previously reported (Dozier et al., 2010; Bernal et al., 2014; Cemin et al., 2017). The predicted dgLys requirement to maximize BWG at d 21 was $99.3 \%(1.24 \%$ dgLys $)$ or $104 \%(1.33 \%$ dgLys) in Exps. 1 or 2, respectively, and this was similar for FCR at d 21 at $98.9 \%(1.24 \%$ dgLys $)$ or $104 \%(1.33 \%$ dgLys) for Exps. 1 or 2, respectively. Previous authors have reported the dgLys concentration required to achieve a minimum (better) FCR was greater than that needed to maximize gain (Dozier et al., 2010; Bernal et al., 2014; Cemin et al., 2017). Whereas in the current set of experiments, the predicted dgLys concentration to maximize gain and minimize FCR were very similar within experiments. The difference in the predicted dgLys requirement for BWG and FCR may be related to the greater daily growth rate and feed intake of birds in the previously published experiments when compared with those utilized in the current set of trials. 
Table 9. Regression equations and coefficients of the influence of digestible lysine requirements of broilers fed different doses of phytase from hatch to $42 \mathrm{~d}$ posthatch (Exps. 1 and 2)

\begin{tabular}{|c|c|c|c|c|}
\hline \multirow[b]{2}{*}{ Trait $(y)$} & \multirow[b]{2}{*}{ Regression equation ${ }^{1}$} & \multirow[b]{2}{*}{$R^{2}$} & \multirow{2}{*}{$\begin{array}{l}\begin{array}{l}\text { Predicted dgLys } \\
\text { requirement }(x),\end{array} \\
\%\end{array}$} & \multirow{2}{*}{$\begin{array}{l}\text { Predicted phytase } \\
\text { dose }(v) \text {, to max } y, \\
\text { FTU } / \mathrm{kg}\end{array}$} \\
\hline & & & & \\
\hline \multicolumn{5}{|l|}{ Experiment 1} \\
\hline \multicolumn{5}{|c|}{ Digestible lysine requirements $(x)$ and optimum phytase dose $(v)$ for broilers from hatch to $21 \mathrm{~d}$ posthatch } \\
\hline BW gain, g & $\begin{array}{c}y=-2,154+62.29 x-0.3140 x^{2}+ \\
0.0263 v-6.3727 \mathrm{e}-{ }^{-6} v^{2}\end{array}$ & 0.64 & 99.3 & 2,065 \\
\hline Feed intake, $\mathrm{g}$ & $y .=-404.3+32.63 x-0.1647 x^{2}$ & 0.29 & 98.9 & - \\
\hline FCR, g:g & $\begin{array}{c}y=4.227+0.0593 x+0.0003 x^{2}- \\
4.4677 \mathrm{e}-{ }^{5} v+1.1017 \mathrm{e}-{ }^{8} v^{2}\end{array}$ & 0.84 & 98.9 & 2,038 \\
\hline \multicolumn{5}{|c|}{ Digestible lysine requirements $(x)$ and optimum phytase dose $(v)$ for broilers from hatch to $42 \mathrm{~d}$ posthatch } \\
\hline BW gain, g & $\begin{array}{c}y=-2,080+93.71 x-0.4768 x^{2}+ \\
0.0599 v-1.3982 \mathrm{e}-{ }^{5} v^{2}\end{array}$ & 0.59 & 98.2 & 2,146 \\
\hline Feed intake, $g$ & $y=2,038+43.29 x-0.2219 x^{2}$ & 0.08 & 97.6 & - \\
\hline FCR, g:g & $\begin{array}{c}y=3.7748-0.0431 x+0.0002 x^{2}- \\
3.5667 \mathrm{e}-{ }^{5} v+7.7502 \mathrm{e}-{ }^{-} v^{2}\end{array}$ & 0.69 & 98.9 & 2,308 \\
\hline Carcass weight $^{3}, \mathrm{~g}$ & $\begin{array}{c}y=1,465+7.9611 x+0.3794 v- \\
2.9318 \mathrm{e}-{ }^{-5} v^{2}-0.0028 x v\end{array}$ & 0.14 & - & - \\
\hline Breast weight $^{3}, \mathrm{~g}$ & $\begin{array}{c}y=218+5.2906 x+0.1405 v \\
-0.0014 x v\end{array}$ & 0.18 & - & - \\
\hline Breast, $\%$ carcass & $y=-29.46+1.2472 x-0.0062 x^{2}$ & 0.17 & 99.71 & - \\
\hline \multicolumn{5}{|c|}{ Experiment 2} \\
\hline \multicolumn{5}{|c|}{ Digestible lysine requirements $(x)$ and optimum phytase dose $(v)$ for broilers from hatch to $21 \mathrm{~d}$ posthatch } \\
\hline BW gain, $\mathrm{g}$ & $\begin{array}{c}y=-614+28.06 x-0.1326 x^{2}+ \\
0.0417 v-9.7264 \mathrm{e}-v^{2}\end{array}$ & 0.35 & 104.0 & 2,130 \\
\hline FCR, g:g & $\begin{array}{c}y=2.5967-0.0229 x+0.0001 x^{2}- \\
6.8104 \mathrm{e}-{ }^{5} \mathrm{~V}+1.7125 \mathrm{e}-{ }^{8} v^{2}\end{array}$ & 0.78 & 104.0 & 1,990 \\
\hline AID lysine, $\%$ & $y=85.699+0.06425 x$ & 0.07 & $>104.0$ & - \\
\hline
\end{tabular}

${ }^{1}$ Regression equations were determined using linear and quadratic estimates for both phytase and digestible lysine concentration in the diet as well as the interaction. Non-significant effects were removed from the model. - unable to predict based on the model.

The effect of phytase dose on the predicted dgLys requirement was different depending on the parameter evaluated and may be reflective of the birds' use of lysine within the body. For example, there was no effect of phytase on the predicted dgLys requirement when using FI as the parameter. However, the phytase dose predicted to maximize BWG and minimize FCR was between 1,990 and 2,308 FTU/kg, regardless of the concentration of dgLys in the diet. Previous authors have reported significant improvements in FCR of broilers fed diets marginally deficient in $\mathrm{P}$ and $\mathrm{Ca}$ and supplemented with phytase at 1,500 FTU/kg (Walk et al., 2013, 2014; Gautier et al., 2018). The benefits associated with high doses or superdoses of phytase, particularly on feed efficiency, have been attributed to near complete destruction of dietary phytate in the gizzard (Walk et al., 2014) and ileum (Sommerfeld et al., 2018) and significant improvements in the AID of amino acids (Beaulac, 2015) which resulted in improvements in BWG without significant increases in FI.

Muscle growth and deposition are dependent on lysine concentration in the diet, particularly breast muscle development in poultry (Bernal et al., 2014). In the current trial, carcass weight (Fig. 3) and breast meat weight (Fig. 4) were influenced by dgLys concentration in the diets and phytase dose. Increasing the predicted phytase dose from 1,527, 1,904, 2,281 to 2,658 FTU/kg resulted in maximum carcass weight as the dgLys requirement in the diet decreased from $104,96,88$, or $80 \%(1.33,1.23,1.13$. or $1.02 \%$ dgLys in the starter diets and $1.09,1.01$, 0.92 , or $0.84 \%$ dgLys in the grower diets), respectively. Similarly, breast weight was maximized at $3,000 \mathrm{FTU} / \mathrm{kg}$ in birds fed 96,88 , or $80 \%$ of the dgLys requirement $(1.23,1.13$, or $1.02 \%$ dgLys in the starter diets and $1.01,0.92$, or $0.84 \%$ dgLys in the grower diets), respectively.

It is well documented that phytase supplementation improves AID of amino acids (Cowieson and Bedford, 2009), with a greater impact on cysteine $(+16 \%)$, glycine $(+7 \%)$, serine $(+8 \%)$, or proline $(+10 \%)$ compared with methionine $(+1 \%)$ or lysine (+4\%; Walk and Rama Rao, 2018). In the current experiment, the concentration of dgLys in the diet and phytase dose had a large and significant interactive effect on the AID of amino acids. 


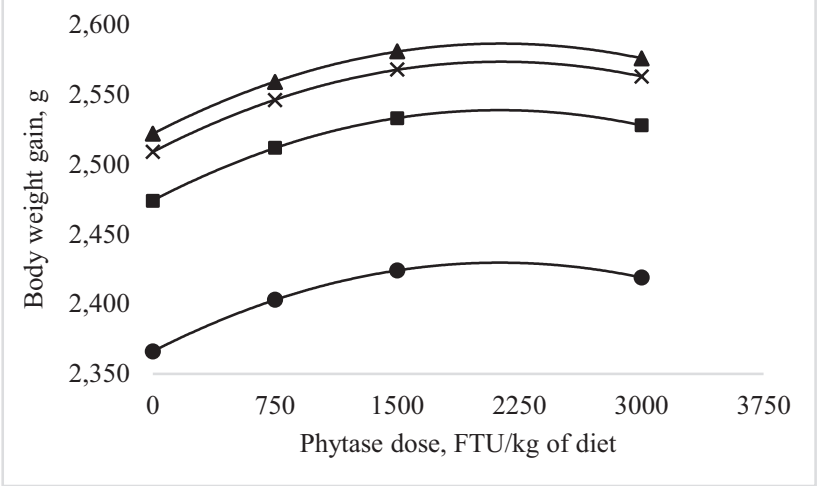

Figure 1. Predicted effect of phytase dose and digestible lysine requirement on body weight gain (grams) of broilers from hatch to $42 \mathrm{~d}$ posthatch (Exp. 1). The model was determined as: $y=-2,080+93.71 x$ $-0.4768 x^{2}+0.0599 v-1.3982 \mathrm{e}-v^{5} v^{2} \cdot R^{2}=0.59 . P<0.0001$. Diets were formulated to contain digestible lysine at $80 \%, \square 88 \%, \boldsymbol{\square} 96 \%$, or $\times 104 \%$ of the requirement according to Cobb 400 breed guidelines (VenCobb 400 Broiler Management Guide, Cobb-Vantress Inc., Siloam Spring, AR); this corresponds to $1.02,1.13,1.23$ and $1.33 \%$ dgLys, respectively, in the starter diets and $0.84,0.92,1.01$ and $1.09 \%$ dgLys, respectively, in the grower diets. The digestible lysine concentration to maximize body weight gain was predicted at $98.2 \%$ of the requirement $(1.23 \%$ dgLys in the starter diet and $1.03 \%$ dgLys in the grower diet), regardless of the dose of phytase supplied in the diet. The dose of phytase to maximize body weight gain was predicted at 2,146 FTU/kg of diet, regardless of the digestible lysine concentration of the diet.

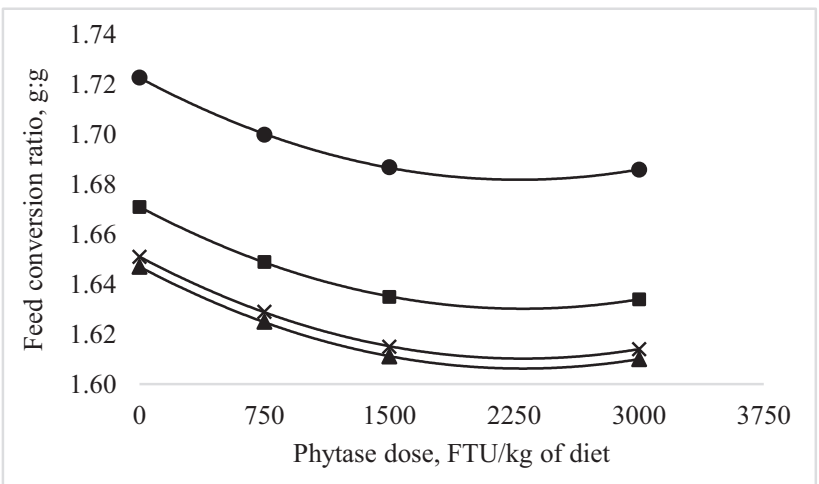

Figure 2. Predicted effect of phytase dose and digestible lysine requirement on feed conversion ratio of broilers from hatch to $42 \mathrm{~d}$ posthatch (Exp. 1). The model was determined as: $y=3.7748-0.0431 x+$ $0.0002 x^{2}-3.5667 \mathrm{e}-5+7.7502 \mathrm{e}-{ }^{-} v^{2} \cdot R^{2}=0.69 . P<0.0001$. Diets were formulated to contain digestible lysine at $80 \%$, $88 \%$, $\mathbf{\Delta} 96 \%$, or $\times 104 \%$ of the requirement according to Cobb 400 breed guidelines (VenCobb 400 Broiler Management Guide, Cobb-Vantress Inc., Siloam Spring, AR); this corresponds to $1.02,1.13,1.23$, and $1.33 \%$ dgLys, respectively, in the starter diets and $0.84,0.92,1.01$, and $1.09 \%$ dgLys, respectively, in the grower diets. The digestible lysine concentration to maximize (reduce) feed conversion ratio was predicted at $98.9 \%$ of the requirement $(1.24 \%$ dgLys in the starter diet and $1.04 \%$ dgLys in the grower diet), regardless of the dose of phytase supplied in the diet. The dose of phytase to minimize feed conversion ratio was predicted at 2,308 FTU/kg of diet, regardless of the digestible lysine concentration of the diet.

For example, phytase supplementation up to 1,500 FTU/kg improved the AID of most amino acids when birds were fed diets containing 80 to $88 \%$ of the dgLys requirement (1.02 to $1.13 \%$ dgLys).

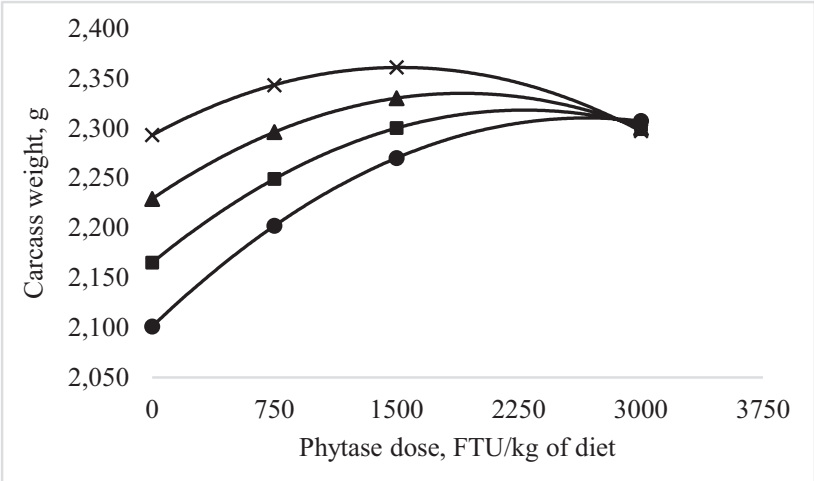

Figure 3. Predicted effect of phytase dose $\times$ digestible lysine concentration on carcass weight (grams) of broilers at $42 \mathrm{~d}$ posthatch (Exp. 1). The model was determined as $y=1,465+7.9611 x+0.3794 v$ $-2.9318 \mathrm{e}-v^{5}-0.0028 x v . R^{2}=0.14 . P<0.0001$. Diets were formulated to contain digestible lysine at $80 \%, \quad 88 \%, \boldsymbol{\wedge} 96 \%$, or $\times 104 \%$ of the requirement according to Cobb 400 breed guidelines (VenCobb 400 Broiler Management Guide, Cobb-Vantress Inc., Siloam Spring, AR); this corresponds to $1.02,1.13,1.23$ and $1.33 \%$ dgLys, respectively, in the starter diets and 0.84, 0.92, 1.01, and 1.09\% dgLys, respectively, in the grower diets. Carcass weight was greatest (maximum) in birds fed 104\% of the digestible lysine requirement $(1.33 \%$ dgLys in the starter diet and $1.09 \%$ dgLys in the grower diet) with 1,527 FTU of phytase $/ \mathrm{kg}$ diet. At 80,88 , or $96 \%$ of the digestible lysine requirement ( 1.02 or $0.84 \%$ dgLys, 1.13 or $0.92 \%$ dgLys, or 1.23 or $1.01 \%$ dgLys in the starter or grower, respectively) the predicted dose of phytase required to maximize carcass weight was $2,658,2,281$, or $1,904 \mathrm{FTU} / \mathrm{kg}$ of diet, respectively.

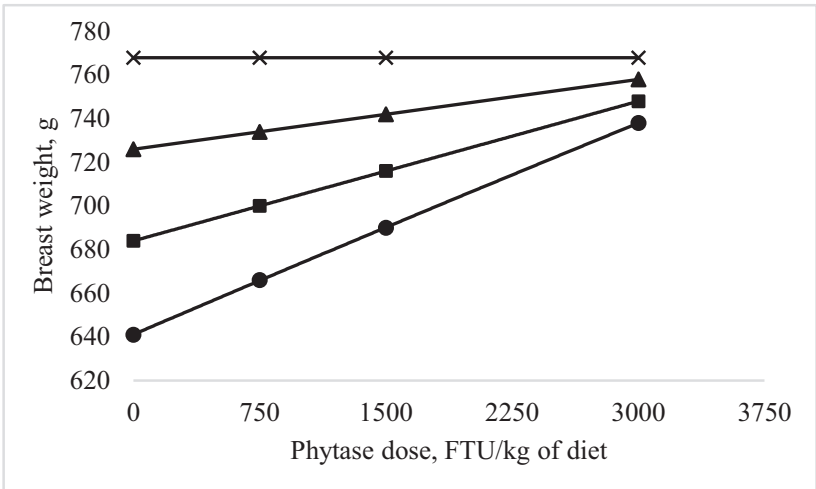

Figure 4. Predicted effect of phytase dose $\times$ digestible lysine concentration on breast meat weight of broilers at $42 \mathrm{~d}$ posthatch (Exp. 1). The model was determined as: $y=218+5.2906 x+0.1405 v-0.0014 x v$. $R^{2}=0.18 . P<0.0001$. Diets were formulated to contain digestible lysine at $80 \%, \square 8 \%, \boldsymbol{\Delta} 96 \%$, or $\times 104 \%$ of the requirement according to Cobb 400 breed guidelines (VenCobb 400 Broiler Management Guide, Cobb-Vantress Inc., Siloam Spring, AR); this corresponds to $1.02,1.13,1.23$, and $1.33 \%$ dgLys, respectively, in the starter diets and $0.84,0.92,1.01$, and $1.09 \%$ dgLys, respectively, in the grower diets. The predicted optimum breast weight was achieved at $\geq 104 \%$ of the digestible lysine requirement $(>1.33 \%$ dgLy in the starter and $>1.09 \%$ dgLys in the grower) with 0 FTU of phytase $/ \mathrm{kg}$ diet. At 80,88 or $96 \%$ of the digestible lysine requirement ( 1.02 or $0.84 \%$ dgLys, 1.13 or $0.92 \%$ dgLys, or 1.23 or $1.01 \%$ dgLys in the starter or grower, respectively) the predicted dose of phytase to maximize breast weight was $\geq 3,000$ FTU/kg of diet.

However, there was no effect of phytase supplementation at any dose on the AID of amino acids in birds fed diets containing 96 to $104 \%$ of the dgLys requirement ( 1.23 to $1.33 \%$ dgLys). Previous 
authors have also reported greater effects of 500 FTU/kg of phytase in lysine-deficient diets when compared with lysine-sufficient diets (Ravindran et al., 2001; Selle et al., 2007). The binding of phytate or phytate esters specifically to dietary lysine, whether supplemental lysine or lysine as a component of proteins and peptides within feedstuffs, is not clear. It is thought lysine, as a polar and basic amino acid, will form strong complexes with the negatively charged phytate molecule, particularly at low pH (Selle and Ravindran, 2007). However, Onyango et al. (2008) reported no significant effect of phytate on the rate of absorption of L-lysine $\mathrm{HCl}$ from the jejunum of 3-wk-old broiler chicks. In an in vitro evaluation of free amino acid binding to phytate in feedstuffs, Rutherfurd et al. (2004) reported very little effects of phytate from corn or soybean meal on the binding of lysine at $\mathrm{pH}$ 2.5 or 5.5. In addition, the lysine concentration of endogenous secretions in the gastrointestinal tract of broilers is low compared with threonine or leucine (Adedokun et al., 2011). Therefore, the antinutrient effects of phytate or lower phytate esters on lysine uptake and utilization are most likely associated with reductions in endogenous protease activity (Liu et al., 2009; Yu et al., 2012). An effect that is magnified in lysine-deficient diets where the majority of the dietary lysine is coming from the less digestible plant-based ingredients when compared with those containing lysine $\mathrm{HCl}$.

Oven drying of the ileal digesta prior to amino acid analysis, using methods similar to those previously described when evaluating amino acid digestibility (Ravindran et al., 2001; Coweison et al., 2006), may have influenced the AID of amino acids (Dale et al., 1985; Lagos and Stein, 2018). Lagos and Stein (2018) reported the standardized ileal digestibility of amino acids and crude protein by pigs fed 3 sources of soybean meal or 2 sources of distillers dried grains with solubles was significantly greater in oven dried $\left(60^{\circ} \mathrm{C}\right)$ samples when compared with freeze dried samples. The authors concluded oven drying of ileal digesta samples results in loss of nitrogen and amino acids and therefore greater standardized ileal digestibility values. Oven drying increased the SID of leucine by $3.1 \%$ or lysine by $8.7 \%$ in soybean meal and tryptophan by $2.2 \%$ or lysine by $13.5 \%$ in distillers dried grains with solubles when compared with the freeze dried samples (Lagos and Stein, 2018). Dale et al. (1985) reported no effect of drying method (freeze dried vs. oven dried at $60{ }^{\circ} \mathrm{C}$ ) on the true amino acid availability values for soybean meal or poultry offal meal fed to White Leghorn roosters, except oven drying increased digestibility of alanine, arginine, or lysine. The previous results from Dale et al. (1985) and Lagos and Stein (2018) indicate the AID of amino acids reported in the current trial may be greater than what would have been reported if the samples were freeze dried. However, in the current experiment, the digesta samples were all exposed to the same drying conditions and any denaturation of amino acids, particularly lysine, arginine, or alanine would have occurred equally between the experimental diets. Therefore, the effect of treatment on the AID of amino acids can still be described as reported because the magnitude of the response to phytase would be the same, regardless of the drying conditions. In addition, the AID coefficients for amino acids in the current trial are similar to the AID of amino acids reported by Cowieson et al. (2006) and Olojede et al. (2018) using similar drying conditions or greater than those reported by Ravindran et al. (2001), also using digesta samples dried at $80^{\circ} \mathrm{C}$. The absolute amino acid digestibility coefficients obtained from any experiment are an estimate of the average amino acid digestibility over the duration of the trial and reported as a point in time measurement. Differences in the digestibility coefficients between the experiments may be associated with numerous factors, such as age of birds, diet composition, marker type, assay method, drying method, and nutrient intake (Dale et al., 1985; Fan et al., 1994; Ravindran et al., 2005; Bryden and Li, 2010; Lagos and Stein, 2018). Therefore, while oven drying the samples in the current experiment may have increased the reported AID coefficients, the most important factor was the relative effect phytase dose and dgLys on AID which was supported by growth performance data. In this regard, the use of digestibility coefficients alone and comparisons between experiments to describe the effect of phytase (or enzymes in general) needs careful consideration, regardless of method employed, due to the previously described factors that can have great influence on digestibility coefficients.

In the current set of trials, in addition to graded concentrations of dgLys, the diets were marginally deficient in both $\mathrm{Ca}$ and $\mathrm{P}$. This was done to mimic typical dietary conditions of phytase supplementation and cannot be ignored when discussing the effects of phytase dose on the predicted dgLys requirements. However, in P-deficient diets, FI is generally reduced and phytase supplementation improves BWG through provision of $\mathrm{P}$ and an increase in intake. The lack of an effect of phytase on FI and the significant effect of dgLys on all parameters evaluated indicate the most limiting 
nutrient in the experimental diets was lysine rather than $\mathrm{P}$ or $\mathrm{Ca}$.

In conclusion, the predicted concentration of dgLys to maximize performance, carcass weight, breast meat weight, or AID was different depending on the parameter evaluated and the dose of phytase employed. Maximum BWG and minimum FCR were achieved at 1,990 to $2,308 \mathrm{FTU} / \mathrm{kg}$ of diet, regardless of the concentration of dgLys. These results confirm previously reported benefits of superdoses of phytase on growth performance and FCR, presumably through nearly complete destruction of phytate and more efficient postabsorptive utilization of amino acids. In contrast, the phytase dose required to maximize AID of all amino acids was between 750 and 1,500 FTU/ $\mathrm{kg}$ of diet and only in diets containing 80 to $88 \%$ of the dgLys requirement ( 1.02 to $1.13 \%$ dgLys). Whereas, for carcass parameters, as dgLys in the diet decreased from 104 to $80 \%$ of the requirement ( 1.33 to $1.02 \%$ dgLys in the starter diet to 1.09 to $0.84 \%$ dgLys in the grower diet) the amount of phytase required to maximize carcass weight or breast meat weight increased from 1,527 FTU/ $\mathrm{kg}$ to $3,000 \mathrm{FTU} / \mathrm{kg}$. The effect of phytase dose on lysine sparing, at least for carcass parameters and growth performance, appears to be quite substantial. These benefits may be attributed to improvements in endogenous protease efficacy and postabsorptive improvements in amino acid utilization, greater than those reported with AID alone, rather than a direct effect of phytate destruction on endogenous losses or binding of phytate to lysine.

\section{LITERATURE CITED}

AOAC. 2006. Official methods of analysis of AOAC international. 18th ed., Association of Official Analytical Chemists, Gaithersburgs, MD.

Adedokun, S. A., O. Adeola, C. M. Parsons, M. S. Lilburn, and T. J. Applegate. 2011. Factors affecting endogenous amino acid flow in chickens and the need for consistency in methodology. Poult. Sci. 90:1737-1748. doi:10.3382/ ps.2010-01245

Beaulac, K. 2015. The effects of graded levels of phytase in broiler diets on growth, intestinal development, and nutrient digestibility. PhD dissertation. University of Saskatchewan, Canada.

Beeson, L. A., C. L. Walk, M. R. Bedford, and O. A. Olukosi. 2017. Hydrolysis of phytate to its lower esters can influence the growth performance and nutrient utilization of broilers with regular or super doses of phytase. Poult. Sci. 96:2243-2253. doi:10.3382/ps/pex012

Bernal, L. E. P., F. C. Tavernari, H. S. Rostagno, and L. F. T. Albino. 2014. Digestible lysine requirements of broilers. Braz. J. Poult. Sci. 16:49-55. doi:10.1590/ S1516-635X2014000100007
Bryden, W. L. and X. Li. 2010. Amino acid digestibility and poultry feed formulation: expression, limitations and application. R. Bras. Zootec. 39:279-287. doi:10.1590/ S1516-35982010001300031

Cemin, H. S., S. L. Vieira, C. Stefanello, M. Kipper, L. Kindlein, and A. Helmbrecht. 2017. Digestible lysine requirements of male broilers from 1 to 42 days of age reassessed. Plos One 12:e0179665. doi:10.1371/journal.pone.0179665

Cowieson, A. J., T. Acamovic, and M. R. Bedford. 2006. Supplementation of corn-soy-based diets with an Eschericia coli-derived phytase: Effects on broiler chick performance and the digestibility of amino acids and metabolizability of minerals and energy. Poult. Sci. 85:1389-1397. doi:10.1093/ps/85.8.1389

Cowieson, A. J., and M. R. Bedford. 2009. The effect of phytase and carbohydrase on ileal amino acid digestibility in monogastric diets: Complimentary mode of action? World's Poult. Sci. J. 65:609-624. doi:10.1017/ S0043933909000427

Cowieson, A. J., and V. Ravindran. 2007. Effect of phytic acid and microbial phytase on the flow and amino acid composition of endogenous protein at the terminal ileum of growing broiler chickens. Br. J. Nutr. 98:745-752. doi:10.1017/S0007114507750894

Cowieson, A. J., V. Ravindran, and P. H. Selle. 2008. Influence of dietary phytic acid and source of microbial phytase on ileal endogenous amino acid flows in broiler chickens. Poult. Sci. 87:2287-2299. doi:10.3382/ps.2008-00096

Dale, N., H. L. Fuller, G. M. Pesti, and R. Dixon Phillips. 1985. Freeze drying versus oven drying of excreta in true metabolizable energy, nitrogen-corrected true metabolizable energy, and true amino acid availability bioassays. Poult. Sci. 64:362-365. doi:10.3382/ps.0640362

Dozier, W. A., III, A. Corzo, M. T. Kidd, P. B. Tillman, J. P. McMurtry, and S. L. Branton. 2010. Digestible lysine requirements of male broilers from 28 to 42 days of age. Poult. Sci. 89:2173-2182. doi:10.3382/ps.2010-00710

European Commission. 2009. Commission Regulation (EC) 152/2009 of 27 January 2009 laying down the methods of sampling and analysis for the official control of feed. OJEU. 52:1-130.

Engelen, A. J., F. C. van der Heeft, P. H. Randsdorp, W. A. Somers, J. Schaefer, and B. J. van der Vat. 2001. Determination of phytase activity in feed by a colorimetric enzymatic method: Collaborative interlaboratory study. J. AOAC Int. 84:629-633.

Fan, M. Z., W. C. Sauer, R. T. Hardin, and K. A. Lien. 1994. Determination of apparent ileal amino acid digestibility in pigs: Effect of dietary amino acid level. J. Anim. Sci. 72:2851-2859. doi:10.2527/1994.72112851x

Gautier, A. E., C. L. Walk, and R. N. Dilger. 2018. Effects of a high level of phytase on broiler performance, bone ash, phosphorus utilization, and phytate dephosphorylation to inositol. Poult. Sci. 97:211-218. doi:10.3382/ps/pex291

González-Vega, J. C., C. L. Walk, M. R. Murphy, and H. H. Stein. 2016. Requirement for digestible calcium by 25 to $50 \mathrm{~kg}$ pigs at different dietary concentrations of phosphorus as indicated by growth performance, bone ash concentration, and calcium and phosphorus balances. J. Anim. Sci. 94:5272-5285. doi:10.2527/jas.2016-0751

Lagos, L. V. and H. H. Stein. 2018. Effect of drying method of ileal digesta on the digestibility of crude protein and amino acids by pigs. J. Anim. Sci. 96(Suppl.S2):181. doi:10.1093/jas/sky073.333 
Liu, N., Y. J. Ru, F. D. Li, J. P. Wang, and X. Q. Lei. 2009. Effect of dietary phytate and phytase on proteolytic digestion and growth regulation of broilers. Arch. Anim. Nutr. 63:292-303. doi:10.1080/17450390903020422

Olojede, O. C., M. J. Ford, J. P. Jacob, T. Ao, A. J. Pescatore, and S. A. Adedokun. 2018. The effect of drying method temperature, collection method, and marker type on apparent ileal amino acid digestibility in 21-day-old broilers fed corn-soybean meal-barley based diet. Poult. Sci. 97:2106-2112. doi:10.3382/ps/pey049

Onyango, E. M., E. K. Asem, and O. Adeola. 2008. Phytates reduce uptake of leucine and glutamate but not lysine and glucose from the intestinal lumen of chickens: Short communication. Acta Vet. Hung. 56:511-514. doi:10.1556/ AVet.56.2008.4.8

Ravindran, V., S. Cabahug, G. Ravindran, and W. L. Bryden. 1999. Influence of microbial phytase on apparent ileal amino acid digestibility of feedstuffs for broilers. Poult. Sci. 78:699-706. doi:10.1093/ps/78.5.699

Ravindran, V., L. I. Hew, G. Ravindran, and W. L. Bryden. 2005. Apparent ileal digestibility of amino acids in dietary ingredients for broiler chickens. Anim. Sci. 81:85-97. doi:10.1079/ASC42240085

Ravindran, V., P. H. Selle, G. Ravindran, Morel PCH, A. K. Kies, and W. L. Bryden. 2001. Microbial phytase improves performance, apparent metabolizable energy, and ileal amino acid digestibility of broilers fed a lysine-deficient diet. Poult. Sci. 80:338-344. doi:10.1093/ps/80.3.338

Rutherfurd, S. M., T. K. Chung, and P. J. Moughan. 2004. The effect of a commercial microbial phytase preparation on the in vitro release of phosphorus and amino acids from selected plant feedstuffs supplemented with free amino acids. J. Anim. Feed Sci. 13:677-690. doi:10.1093/ps/86.4.665

Selle, P. H., A. J. Cowieson, N. P. Cowieson, and V. Ravindran. 2012. Protein-phytate interactions in pig and poultry nutrition: A reappraisal. Nutr. Res. Rev. 25:1-17. doi:10.1017/S0954422411000151

Selle, P. H., and V. Ravindran. 2007. Microbial phytase in poultry nutrition. Anim. Feed Sci. Technol. 135:1-41. doi:10.1016/j.anifeedsci.2006.06.010

Selle, P. H., V. Ravindran, G. Ravindran, and W. L. Bryden. 2007. Effects of dietary lysine and microbial phytase on growth performance and nutrient utilization of broiler chickens. Asian-Aust. J. Anim. Sci. 20:1100-1107. doi:10.5713/ajas.2007.1100

Sommerfeld, V., S. Kunzel, M. Schollenberger, I. Kuhn, and M. Rodehutscord. 2018. Influence of phytase or myo-inositol supplements on performance and phytate degradation products in the crop, ileum and blood of broiler chickens. Poult. Sci. doi:10.3382/ps/pex390

Walk, C. L., M. R. Bedford, T. S. Santos, D. Paiva, J. R. Bradley, H. Wladecki, C. Honaker, and A. P. McElroy. 2013. Extra-phosphoric effects of superdoses of a novel microbial phytase. Poult. Sci. 92:719-725. doi:10.3382/ ps.2012-02727

Walk, C. L., and S. V. Rama Rao. 2018. High doses of phytase on growth performance and apparent ileal amino acid digestibility of broilers fed diets with graded concentrations of digestible sulfur amino acids. Poult. Sci. 97:3610 3621. doi: $10.3382 / \mathrm{ps} /$ pey 218

Walk, C. L., T. T. Santos, and M. R. Bedford. 2014. Influence of superdoses of a novel microbial phytase on growth performance, tibia ash, and gizzard phytate and inositol in young broilers. Poult. Sci. 93:1172-1177. doi:10.3382/ ps.2013-03571

Yu, S., A. Cowieson, C. Gilbert, P. Plumstead, and S. Dalsgaard. 2012. Interactions of phytate and myo-inositol phosphate esters (IP1-5) including IP5 isomers with dietary protein and iron and inhibition of pepsin. J. Anim. Sci. 90:1824 1832. doi:10.2527/jas.2011-3866 